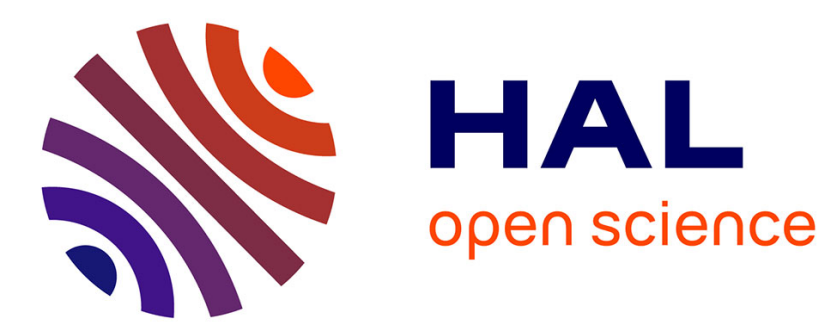

\title{
Hominin diversity in East Asia during the Middle Pleistocene: A premolar endostructural perspective 12
} Lei Pan, Jean Dumoncel, Arnaud Mazurier, Clément Zanolli

\section{To cite this version:}

Lei Pan, Jean Dumoncel, Arnaud Mazurier, Clément Zanolli. Hominin diversity in East Asia during the Middle Pleistocene: A premolar endostructural perspective 12 . Journal of Human Evolution, 2020, 148, pp.102888. 10.1016/j.jhevol.2020.102888 . hal-03002831

\section{HAL Id: hal-03002831 \\ https://hal.science/hal-03002831}

Submitted on 12 Nov 2020

HAL is a multi-disciplinary open access archive for the deposit and dissemination of scientific research documents, whether they are published or not. The documents may come from teaching and research institutions in France or abroad, or from public or private research centers.
L'archive ouverte pluridisciplinaire HAL, est destinée au dépôt et à la diffusion de documents scientifiques de niveau recherche, publiés ou non, émanant des établissements d'enseignement et de recherche français ou étrangers, des laboratoires publics ou privés. 
1 Hominin diversity in East Asia during the Middle Pleistocene: A premolar endostructural perspective

3 Lei Pan a, b, 1 , Jean Dumoncel ${ }^{\mathrm{c}}$, Arnaud Mazurier ${ }^{\mathrm{d}}$, Clément Zanolli e, *

$4 \quad{ }^{a}$ Key Laboratory of Vertebrate Evolution and Human Origins, Institute of Vertebrate Paleontology and

5 Paleoanthropology, CAS, Beijing, China

6 b State Key Laboratory of Palaeobiology and Stratigraphy, Nanjing Institute of Geology and

$7 \quad$ Palaeontology, CAS, Nanjing, China

$8 \quad{ }^{\mathrm{C}}$ Laboratoire AMIS, UMR 5288 CNRS, Université Toulouse III - Paul Sabatier, France

9 d Institut de Chimie des Milieux et Matériaux, UMR 7285 CNRS, Université de Poitiers, 86073 Poitiers,

10 France

$11{ }^{\mathrm{e}}$ Laboratoire PACEA, UMR 5199 CNRS, Université de Bordeaux, France

12

$13 *$ Corresponding author.

14 E-mail address: clement.zanolli@gmail.com (C. Zanolli).

$15 \quad{ }^{1}$ Deceased May 2020

16 Abstract

17 Following the recent studies of East Asian mid-Middle to early Late Pleistocene

18 hominin material, a large spectrum of morphological diversity has been recognized and

19 the coexistence of archaic ('Homo erectus-like') and derived ('modern-like') dental

20 morphological patterns has been highlighted. In fact, for most of these Chinese fossils,

21 generally categorized as 'archaic Homo sapiens' or 'post-H. erectus Homo', the 
22 taxonomic attribution is a matter of contention. With the help of $\mu \mathrm{CT}$ techniques and a

23 deformation-based 3D geometric morphometric (GM) approach, we focused on the

24 morphological variation in the enamel-dentine junction (EDJ) of 18 upper and lower

25 premolars from Chinese Middle Pleistocene hominins. We then compared our results

26 with a number of fossil and modern human groups, including Early Pleistocene $H$.

27 erectus from Sangiran; late Early Pleistocene hominins from Tighenif, Algeria; classic

28 Neanderthals; and modern humans. Our results highlight an evolutionary/chronological

29 trend of crown base reduction, elevation of EDJ topography, and EDJ surface

30 simplification in the hominin groups studied here. Moreover, this study brings insights

31 to the taxonomy/phylogeny of six late Middle Pleistocene specimens whose

32 evolutionary placement has been debated for decades. Among these specimens,

33 Changyang premolars show features that can be aligned with the Asian H. erectus

34 hypodigm, while Panxian Dadong and Tongzi premolars are more similar to Late

35 Pleistocene Homo. Compared with early to mid-Middle Pleistocene hominins in East

36 Asia, late Middle Pleistocene hominins evince an enlarged morphological variation. A

37 persistence of archaic morphotypes and possible admixture among populations during

38 the late Middle Pleistocene are discussed.

39

40 1. Introduction

41 Dental evidence suggests that Eurasian Early and Middle Pleistocene hominins,

42 including those from Central Asia (Martinón-Torres et al., 2008), continental East Asia 
43 (Bailey and Liu, 2010; Liu et al., 2013, 2017; Xing et al., 2014, 2016, 2018; Zanolli et

44 al., 2018) and insular Southeast Asia, had a relatively independent evolutionary course

45 compared with African hominins (Martinón-Torres et al., 2007; Bermúdez de Castro

46 and Martinón-Torres, 2013; Kaifu, 2017). From the early to mid-Middle Pleistocene,

47 hominin remains found in the Asian continent are mostly assigned to Homo erectus

48 (Kaifu et al., 2005; Martinón-Torres et al., 2008; Zanolli, 2013; Xing et al., 2014, 2016).

49 However, the high-degree of morphological variation of the Asian dental remains

50 (Zanolli et al., 2012, 2018a; Liu et al., 2013; Xing et al., 2018, 2019) suggests the

51 (co)existence of derived (modern H. sapiens-like) and archaic morphotypes in the

52 Middle Pleistocene. This complex scenario gives rise to a number of questions

53 regarding the routes of dispersal, possible interactions and gene flow between lineages

54 in the mid-Middle to early Late Pleistocene, before the attested presence of

55 anatomically modern humans (Liu et al., 2015).

56 In the late Pleistocene Chinese hominin fossil record, the taxonomic status and

57 phylogenetic relationships with earlier, contemporaneous and later human lineages

58 remains unclear. Part of this is probably due to the limited sample size and the

59 heterogeneity of expression of archaic and derived traits in the mid- to late Middle

60 Pleistocene 'non- $H$. erectus' human record. For instance, the late Middle Pleistocene

61 dental remains from Panxian Dadong, even if limited to four isolated teeth, retain some

62 archaic traits in the anterior dentition, including a weakly expressed finger-like

63 tuberculum dentale on the upper central incisor and robust incisor and canine crowns, 
64 in association with derived features in most teeth (symmetrical canine crown without

65 cingulum, modern-like premolar crown morphology; Liu et al., 2013). Similarly, the

66 late Middle Pleistocene teeth from Tongzi, even if penecontemporaneous with late

67 representatives of $H$. erectus, differ from the typical condition seen in the latter group

68 and show a series of derived traits that are more commonly seen in Late Pleistocene

69 Homo, including: the absence of tuberculum dentale on the upper incisor, simplified

70 and symmetrical premolar crowns without grooves and ridges on the buccal aspect, and

71 mesiodistally compressed upper molars (Wu, 1984; Xing et al., 2019). Conversely,

72 dental remains from other late Middle to early Late Pleistocene populations such as

73 Chaoxian, Changyang and Xujiayao express a degree of archaic, H. erectus-like

74 features - see external crown morphology in Xing et al. $(2015,2016)$ and Bailey and

75 Liu (2010), and root canal configuration in Pan et al. (2019). Taphonomic factors and

76 occlusal wear have also erased parts of the external tooth morphology, thus adding to

77 the confusion concerning the evolutionary interpretations of these specimens (Liu et al.,

78 2013; Xing et al., 2015, 2019; Pan and Zanolli, 2019). However, even if the external

79 morphology is altered, diagnostic taxonomic and phylogenetic information may still be

80 preserved in the internal structure of teeth, and their internal signature can still be

81 extracted using the methods developed in virtual paleoanthropology (Skinner et al.,

82 2008b; Xing et al., 2014, 2016, 2018; Weber, 2015; Zanolli et al., 2018; Pan and Zanolli, 83 2019).

84 We used X-ray $\mu \mathrm{CT}$ scanning and 3D image processing techniques to investigate 
85 the inner structure of six late Middle Pleistocene premolar specimens from the sites of

86 Changyang (PA76, PA81), Tongzi (PA873), Panxian Dadong (PA 1577 and PA 1578)

87 and Chaoxian (Chaoxian), whose taxonomic attribution is controversial. In order to

88 characterize these specimens, we focus here on the enamel-dentine junction (EDJ)

89 morphology. This interface results from the membrana praeformativa that configures

90 the outer enamel surface (OES) during tooth growth (Corruccini, 1987). In mature teeth,

91 it preserves diagnostic morphological information, even when the occlusal enamel is

92 worn. It is thus recognized as a reliable taxonomic proxy to distinguish between

93 hominid taxa (even at the subspecies level) and can also bring hominid phylogenetic

94 insights (Weber, 2001; Skinner, 2008; Skinner et al., 2008a; Braga et al., 2010;

95 Macchiarelli et al., 2013; Pan et al., 2016; Zanolli et al., 2019).

96 Comparing with a number of fossil and modern human specimens/samples,

97 including Chinese early to mid-Middle Pleistocene $H$. erectus from the sites of

98 Zhoukoudian, Hexian, Xichuan and Yiyuan, the aims of this study are: (1) to examine

99 the ability of premolar EDJ morphological information to discriminate among a

100 selection of fossil and modern human premolar samples; (2) to document the

101 morphological variability of mid- to late Middle Pleistocene human premolars in East

102 Asia; and (3) to re-evaluate the taxonomic affinities of six late Middle Pleistocene

103 specimens. 
The Chinese Middle Pleistocene hominin sample consists of two groups; a map of their location is shown in Supplementary Online Material (SOM) Figure S1. The first group includes early to mid-Middle Pleistocene H. erectus (HEC, $n=12)$ from the sites of Zhoukoudian, Hexian, Xichuan and Yiyuan, with a chronological range from 800 to $282 \mathrm{ka}$ (Table 1). Note that the specimens from Xichuan County, Hubei Provence lack accurate stratigraphic context, but their morphological signature a priori places them

113 close to Zhoukoudian H. erectus (Wu and $\mathrm{Wu}, 1982$; Wu and Poirier, 1995). The

114 allocation of Xichuan hominins to East Asian H. erectus is further supported by a recent 115 comparative study (Xing et al., 2018) on the dental inner structure of Chinese Middle 116 Pleistocene $H$. erectus. The second group is represented by six premolars from three 117 mid- to late Middle Pleistocene sites (Changyang, Tongzi, Panxian Dadong and 118 Chaoxian). These specimens do not have a clear taxonomic attribution, as in previous 119 studies they were classified as archaic or premodern $H$. sapiens, or were categorized as 120 non-H. erectus Homo (Xing et al., 2019) (and are thus regarded here a priori as Homo 121 sp. from China, HSPC). We compared the Chinese specimens with 56 fossil and extant 122 human specimens (Table 1), including Javanese Early Pleistocene H. erectus (HEJ) 123 specimens from Sangiran (Grine, 1994; Kaifu et al., 2005); North African late Early 124 Pleistocene hominins (HNA) from Tighenif (Zanolli and Mazurier, 2013); Neanderthals 125 (NEA) from Krapina and La Chaise (Macchiarelli et al., 2006; NESPOS database, 126 2020), and modern H. sapiens (MHS) from Africa and Eurasia (Pan et al., 2017). 


\subsection{Methods}

Tooth wear stages were scored according to the standard proposed by Smith (1984).

130 For the Neanderthal and modern $H$. sapiens specimens, we selected only premolars

131 without dentine exposure on the occlusal surface. However, for the Chinese Middle

132 Pleistocene specimens, because of the limited available sample, we included all

133 specimens with wear degree less than stage 3 ("full cusp removal and/or moderate

134 dentine patches"; Smith, 1984:45).

135 Information on the crown outer and inner morphology-non-metric features, 2D

136 geometric morphometrics (GM) on the OES - has been reported for most of the HEC

137 and HSPC specimens in previous studies (Black et al., 1933; Chia, 1957; Wu and Wu,

138 1982; Chen et al., 1987; Bailey and Liu, 2010; Xing, 2012; Liu et al., 2013; Xing et al.,

139 2014, 2016, 2018, 2019; Liu et al., 2017; Zanolli et al., 2018a). The dental remains

140 from Xichuan (PA524, PA525, PA526, PA527, PA528) and Changyang (PA76, PA81)

141 are reported and their internal structure (as well as that of the Chaoxian specimen)

142 analyzed here for the first time. The terms employed for the morphological descriptions

143 are from Weidenreich (1937), Turner et al. (1991) and Scott and Turner (1997).

144 Microcomputed tomography and processing of the 3D data All Chinese fossil

145 specimens (except for two Zhoukoudian $H$. erectus specimens housed at Uppsala

146 University) were scanned using a $225 \mathrm{kV}$ micro-XCT scanner at the Institute of

147 Vertebrate Paleontology and Paleoanthropology, China according to the following 
parameters: $120-140 \mathrm{kV}$ voltage, $100-120 \mathrm{~mA}$ current, angular step of $0.5^{\circ}$ over a scan

149 angle of $360^{\circ}$. The final volumes were reconstructed with an isotropic voxel size 150 ranging from 40 to $70 \mu \mathrm{m}$. The fossil premolars PMU M3887 and M3549, housed at 151 Uppsala University, were scanned at the Multidisciplinary Laboratory of the The Abdus 152 Salam International Centre for Theoretical Physics (ICTP), Trieste, Italy ( Zanolli et al., 153 2018a).

154 Image stacks were imported into Avizo 9.0 (FEI Visualization Sciences Group), 155 and the images were segmented using semiautomatic procedures and an adaptation of 156 the half-maximum height method (Fajardo et al., 2002; Coleman and Colbert, 2007); 157 the EDJ surfaces were generated using the 'unconstrained smoothing' option. For 11 158 out of 18 Chinese human fossil specimens (marked in Table 1), some cusp tips were 159 worn, so we manually reconstructed the dentine horn tips based on the curvature and 160 orientation of the EDJ at each side of the dentine horns (Smith et al., 2012; Zanolli et 161 al., 2018b). Our reconstructions are depicted in SOM Figure S2.

162 Geometric morphometric analysis We used a recently developed diffeomorphic surface 163 matching (DSM) method to compare the EDJ shapes among hominin groups. This 164 landmark-free, mesh-based approach relies on the construction of average surface 165 models, and the difference between surfaces is interpreted as the amount of deformation 166 needed to align them by using diffeomorphic shape matching (Glaunes and Joshi, 2006;

167 Durrleman et al., 2014). Then deformations between surfaces are mathematically 168 modeled as smooth and invertible functions (i.e., diffeomorphisms; Glaunes and Joshi, 
170 The method estimates an average object configuration or mean shape from a collection

171 of object sets, here the EDJ surfaces, and computes the deformations from the mean

172 shape to each specimen. In addition, a set of initial control points located near its most

173 variable parts, and a set of momenta parameterizing the deformations of the mean shape

174 to each individual are estimated (Durrleman et al., 2012a, b; Beaudet et al., 2016a).

175 This method has been successfully employed in a number of

176 paleontological/paleoanthropological investigations (Beaudet et al., 2016b, 2018;

177 Zanolli et al., 2018; Braga et al., 2019; Pan et al., 2019; Urciuoli et al., 2020). A recent

178 study comparing the discriminative power of 3D landmark-based GM and DSM

179 demonstrated that DSM has the potential to better capture the geometric details that

180 describe tooth shape (Braga et al., 2019).

181 To perform this analysis, as a previous step, at each dental position the EDJ

182 surfaces were manually oriented, then superimposed using the rigid and uniform scale

183 option of the 'align surface' module in Avizo 9.0 (Visualization Sciences Group Inc.).

184 This was done by minimizing the root mean square distance between the points of each

185 specimen to corresponding points on the reference surface using an iterative closest 186 point algorithm.

187 We used the Deformetrica software (https://www.deformetrica.org; Durrleman et 188 al., 2014) to generate a global mean shape (GMS) with a set of diffeomorphisms from 189 the GMS to each individual and the output (control points and deformation momenta) 
used to perform the statistical analyses to explore the EDJ shape variation. An example

191 of the original EDJ surface, the simplified EDJ surface imported in Deformetrica v. 4.3

192 and the output virtual models generated by DSM process is shown in SOM Figure S3

193 (see also SOM Fig. S4 for the output surfaces of all the Chinese fossil specimens after

194 deformations). Using the packages ade4 1.7-13 (Dray and Dufour, 2007) and Morpho

195 v. 2.6 (Schlager et al., 2018) for R v. 3.5.1 (R Development Core Team, 2012), we

196 checked the shape variation of the fossil and recent human groups in a principal

197 component analysis (PCA). Even if the first two components of the PCA account for

198 approximately 40 to $65 \%$ of the total variance in these analyses, there is still some

199 information in the following components. Howerver, visualizing and interpreting a

200 complex space in multiple dimensions is difficult. We computed between-group

201 principal component analyses (bgPCA) to evaluate the degree of shape variation

202 between hominin groups. We used both PCA and bgPCA as the former is mostly a

203 means to explore the morphospace, with the variance spread over multiple axes,

204 whereas bgPCA, through projection of the data onto the principal components of the

205 group averages, represents a viable alternative to discriminant analyses (Mitteroecker

206 and Bookstein, 2011). Nonetheless, when sample size is small and groups are few, the

207 results of bgPCA must be interpreted with care and a number of tests are needed to

208 confirm that group separation is not spurious (Bookstein, 2019; Cardini et al., 2019).

209 As a result, we checked and confirmed that group separation preexisted in the PCA and

210 bgPCA was used to assess group affinity of target specimens. Following the 
211 recommendations of Cardini and Polly (2020), we also computed the cross-validated

212 bgPCA (CV-bgPCA) to confirm that the group distribution is not spurious. The six

213 Chinese late Middle Pleistocene Homo sp. specimens were then projected a posteriori

214 in the bgPCA plot to assess their morphological affinities.

215 The residual of allometric signals were tested using the coefficient of determination

$216\left(\mathrm{R}^{2}\right)$ of a multiple regression (Bookstein, 1991) in which the explicative variable is the

217 EDJ area as proxy for size and the dependent variables are the (bg)PC scores.

219 3. Results

220 3.1. Description of enamel-dentine junction morphologies

221 Here we describe the morphological features on the EDJ of previously unreported

222 material from Xichuan, Changyang and Chaoxian and compared it with a number of

223 Pleistocene and Holocene hominin specimens (see Figs. 1A-V and $2 \mathrm{~A}-\mathrm{S}$ for EDJ

224 surfaces in occlusal view). The Chinese fossil specimens are ordered and described 225 below with regard to dental position.

226 Left maxillary third premolar $\left(\mathrm{P}^{3}, \mathrm{PA} 524\right.$, Xichuan $)$ See Figure 1B. Viewed from the

227 occlusal surface, the crown contour is oval and slightly asymmetrical, the width of the

228 buccal aspect is slightly larger than the lingual aspect, the transverse crest is pronounced

229 and connects the buccal and lingual cusps, forming a small and deep anterior fovea and 230 a larger posterior fovea, and a small tubercle is visible at the mesial aspect of the buccal 
231 cusp base. Along the marginal ridge, no accessory ridge is identified.

232 Left maxillary third premolar $\left(\mathrm{P}^{3}, \mathrm{PA} 76\right.$, Changyang) See Figure 1D. The occlusal

233 outline of the marginal ridges is elliptical and slightly asymmetrical, two faint accessory

234 ridges (one of which is bifurcated at the end) can be seen at the base of the buccal cusp

235 but interrupted in the middle of the small occlusal basin, and no continuous transverse

236 crest is formed. One mesial accessory ridge is identified. Two weakly developed

237 tubercles are visible at the base of the lingual cusp.

238 Right maxillary fourth premolar ( $\mathrm{P}^{4}$, Chaoxian) See Figure 1O. This $\mathrm{P}^{4}$ is attached to a

239 maxilla, whose right $\mathrm{P}^{3}-\mathrm{M}^{1}$ and left $\mathrm{P}^{4}-\mathrm{M}^{2}$ are preserved (Bailey and Liu, 2010). The

240 occlusal basin of this $\mathrm{P}^{4}$ is relatively small compared with the crown base, similar to

241 the condition in $H$. erectus (Fig. 1M, N, P, Q). The crown contour is ovorectangular.

242 The transverse crest is not well expressed and is interrupted by the occlusal basin. In

243 all, compared with the highly crenulated EDJ surface that is expressed at East Asian $H$.

244 erectus (e.g., Xing et al., 2016, 2018; this study), the EDJ of Chaoxian $\mathrm{P}^{4}$ is more similar

245 to the less complex morphology of Indonesian $H$. erectus from Sangiran. Weakly-

246 expressed accessory tubercles are found at the mesial and distal part of the occlusal

247 basin.

248 Left mandibular third premolar ( $\mathrm{P}_{3}, \mathrm{PA} 526$, Xichuan) See Figure 2C. The crown outline

249 of PA526 is asymmetrical and mesiodistally elongated in occlusal view. The transverse

250 crest is well developed and continuous. The mesial fovea is slightly smaller than the

251 distal one, as the latter is born by a wide talonid. An accessory ridge can be found at 
252 the mesial aspect of the lingual cusp, but it does not reach the mesial marginal ridge. At

253 the buccal surface, the mesial vertical groove is better developed than the distal one.

254 Right mandibular third premolar ( $\left.\mathrm{P}_{3}, \mathrm{PA} 527, \mathrm{Xichuan}\right)$ See Figure 2D. The morphology

255 of PA527 is very similar to that of PA526; however, instead of an accessory ridge, a

256 fainted wrinkle is present at the mesial side of the lingual cusp. Like PA526, the mesial

257 vertical groove at the buccal surface is better expressed than the distal one.

258 Right mandibular fourth premolar ( $\mathrm{P}_{4}, \mathrm{PA} 525$, Xichuan) See Figure 2L. The outline of

259 the marginal ridge is ovorectangular with a protruding mesiobuccal angle. The

260 transverse crest is moderately expressed and interrupted. At the occlusal basin, two

261 small, weakly expressed wrinkles are presented at the mesial marginal ridge and the

262 distal side of the lingual cusp. Moreover, a weakly expressed accessory cusp is seen at

263 the distal side of the buccal cusp. On the buccal surface, two vertical grooves are clearly

264 detected.

265 Left mandibular fourth premolar ( $\mathrm{P}_{4}, \mathrm{PA} 528$, Xichuan) See Fig. 2M. The morphology

266 of PA528 is slightly different from that of PA525, but resembles that of the H. erectus

267 specimen M3887 from Zhoukoudian. The occlusal outline of its marginal ridge is also

268 ovorectangular. The transverse crest is well developed and uninterrupted, and the

269 mesial fovea is clearly smaller than the distal fovea. Several accessory cusps can be

270 seen at the distal marginal ridge, and a moderately expressed accessory crest is present

271 at the distal side of the lingual cusp. A moderately expressed wrinkle is visible at the

272 mesial marginal ridge. On the buccal surface, two vertical grooves are well expressed. 
273 Left mandibular fourth premolar ( $\mathrm{P}_{4}, \mathrm{PA} 81$, Changyang) See Figure 2N. The crown

274 contour is ovorectangular, the distal part of the crown being wider than the mesial

275 one. The transverse crest is interrupted by a deep groove and is weakly developed.

276 Mesial and distal accessory ridges for the lingual cusp can be identified, three

277 accessory cusps are seen at the distal part of the fovea posterior, and an accessory

278 ridge is present distally to the buccal cusp and deflects at the center of the occlusal

279 basin. On the buccal surface, the distal vertical groove is more pronounced than the

280 mesial one.

281 The East Asian mid-Middle Pleistocene H. erectus (PA67, 68, 110, 524, 525, 526,

282527, 528, 832, M3887 and Shy071) consistently show a complex morphology, with

283 vertical ridges and crests on the buccal aspect of the EDJ, together with a wrinkled

284 occlusal basin and accessory cusps and crests. In the latter half of the Middle

285 Pleistocene, more variation is observed.

286 For the upper premolars, the $\mathrm{P}^{3}$ PA76 (Fig. 1D) from Changyang retains archaic

287 traits, as it exhibits multiple accessory crests running in the occlusal basin. In

288 comparison with PA76, the $\mathrm{P}^{3} \mathrm{PA} 873$ from Tongzi (Fig. 1E) displays a simple

289 morphology, with a proportionally larger and smoother occlusal basin and three faint

290 occlusal crests running on the internal aspect of the paracone. The mesial and distal

291 marginal ridges of PA873 are more protruding, with numerous small cuspule-like

292 features. A similarly simplified and enlarged occlusal basin than in PA873 is also shown

293 in the $\mathrm{P}^{3}$ PA1577 (Fig. 1F) from Panxian Dadong. The $\mathrm{P}^{4}$ from Chaoxian (Fig. 1O) has 
like' EDJ that is shown in $H$. erectus, the occlusal surface relief of Chaoxian is less complex (but is not comparable to PA873 and 1577, which are more simple and smooth) with a weakly-expressed, interrupted transverse crest.

As for the lower premolars, a previous study on the crown morphology (Liu et al., 2013) showed that the $\mathrm{P}_{3}$ PA1578 (Fig. 2E) from Panxian Dadong exhibits weakly expressed archaic traits and a derived general configuration with respect to the condition in H. erectus. The EDJ outline is more symmetrical in PA1578 than in Early to mid-Middle Pleistocene specimens from Africa and Asia (including the North

304 African specimen Tighenif 2, Indonesian and Chinese H. erectus), but is more 305 asymmetrical than in recent modern humans. Previous analyses of crown geometric 306 morphometrics place the Panxian Dadong premolars close to modern humans (Liu et 307 al., 2013). Studies of the root structure show that, compared with modern humans, PA 3081578 has a robust morphology, although it is more gracile than the root complex usually 309 found in H. erectus (Pan et al., 2019; Pan and Zanolli, 2019). On the other hand, the $\mathrm{P}_{4}$ 310 PA81 (Fig. 2N) from Changyang exhibits a wrinkled occlusal basin, with vertical ridges 311 expressed on the buccal aspect of the EDJ (similar to H. erectus; Fig. 2K-M). The 312 talonid of PA81 is mesiodistally elongated with a minute hypoconid dentine horn (Fig.

$3132 \mathrm{~N})$. In sum, from the six premolar specimens dated to late Middle Pleistocene, despite 314 a small sample size, greater morphological variability (i.e., primitive, $H$. erectus like 
and derived, modern-human like) is observed compared with East Asian H. erectus.

Fig. S4, which illustrates the output surfaces after DSM analyses). Taking into account that some authors have issued cautions about the interpretation of bgPCA results

321 (Bookstein, 2019; Cardini et al., 2019), we present in Figures 3 and 4 the results from both PCA and bgPCA. Results of CV-bgPCA are illustrated in the SOM Figure S5,

323 showing that the groups are separated in a similar way than in the bgPCA (even if 324 inversion of the distribution of points between the negative and positive space along

325 the axes may occur) and that group separation is not spurious. A mild allometric signal

326 is observed along some of the (bg)PCs (SOM Table S1). While size-related component

327 is present, the variation observed in the PCA and bgPCA thus mostly represents shape

328 differences.

PCA and bgPCA yielded consistent results with $H$. erectus, Neanderthals and

330 modern humans roughly distributed in a similar way along the first two axes, even if as

331 expected the bgPCA better separates them (Figs. 3 and 4). In any case, even if slightly

332 more overlapping, the groups identified when observing the morphospace obtained

333 with bgPCA are already present in the PCA. The extreme shape changes along each

334 (bg)PC are shown at the extremities of each axis. Even if comparative late Early to mid-

335 Middle Pleistocene, Late Pleistocene and Holocene Homo groups are closer in the PCA 
336 of $\mathrm{P}^{4}$ (Fig. 3C), H. erectus (including the North African specimen Tighenif 2,

337 Indonesian and Chinese H. erectus) is discriminated from later groups along (bg)PC1

338 (Figs. 3 and 4). (bg)PC1 reflects a chronoevolutionary trend, with lower EDJ in $H$.

339 erectus than in the two other groups, as shown by the extreme shapes at the end of the

340 axes (Figs 3 and 4; see also Figs. 1 and 2). For $\mathrm{P}^{3}$ and $\mathrm{P}^{4}$, H. erectus shows a narrower

341 occlusal basin (buccolingually compressed and small with respect to the crown base)

342 and more internally-positioned dentine horns than in Neanderthals and modern humans

343 (Fig. 3 A-D). As seen in the bgPCA, Neanderthal upper premolars differs from those

344 of modern humans by their mesiodistally wider EDJ and deeper occlusal basin (Fig. 3B,

345 D). For the $\mathrm{P}_{3} \mathrm{EDJ}$, as seen along (bg)PC1, H. erectus exhibits a proportionally more

346 expanded talonid (resulting in a protruding distolingual angle of the crown) than in

347 Neanderthals and modern humans that show more equally developed mesial and distal

348 foveae. Along bgPC2, Neanderthal $\mathrm{P}_{3}$ are separated from those of modern humans due

349 to their smaller occlusal basin (Fig. 4A-B). PC1 and bgPC1 of the $\mathrm{P}_{4} \mathrm{EDJ}$ analyses

350 show that $H$. erectus has low lateral aspects and short dentine horns, with a more

351 buccolingually compressed occlusal basin (and more internally-set metaconid) than in

352 Neanderthals and modern humans (Fig. 4 C, D). bgPC2 discriminates Neanderthals

353 from modern humans, the latter having a lingually-positioned metaconid and

354 buccolingually expanded occlusal basin and more equally developed mesial and distal

355 foveae than in the former (Fig. D). In this context, the Changyang specimens (PA76 $\mathrm{P}^{3}$

356 and $\mathrm{PA} 81 \mathrm{P}_{4}$ ) and the $\mathrm{P}^{4}$ from Chaoxian unambiguously fall close to the late Early 
357 Pleistocene to mid-Middle Pleistocene human groups, showing low EDJ, large crown

358 base and complex surface relief with relatively small occlusal basin —as supported by

359 previous observations on the EDJ surfaces (Figs. 1D, O and $2 \mathrm{~N}$ ). Conversely, the $\mathrm{P}^{3}$

360 PA873 from Tongzi, $\mathrm{P}^{3}$ PA1577 and $\mathrm{P}_{3}$ PA1578 from Panxian Dadong are placed within

361 or very close to the variability of Neanderthals and modern humans (Figs. 3A, B and

$3624 \mathrm{~A}, \mathrm{~B})$.

363 Results of the cross-validation tests performed on the bgPC scores shows that

364 predictive accuracy is robust (Table 2). Correct classification of $88-100 \%$ is obtained

365 in most analyses, except for the $\mathrm{P}^{4}$ analysis, which exhibits slightly more confusion for

366 Neanderthals and modern humans (80\% of correct classification; but $H$. erectus teeth

367 show $100 \%$ discrimination). The $\mathrm{P}^{3} \mathrm{PA} 76$, the $\mathrm{P}^{4}$ Chaoxian and the $\mathrm{P}_{4} \mathrm{PA} 81$ are

368 classified as $H$. erectus. The $\mathrm{P}^{3} \mathrm{PA} 873$ and the $\mathrm{P}_{3} \mathrm{PA} 1578$ are both classified nearly

369 equally as belonging to either modern humans or Neanderthals, while the $\mathrm{P}^{3} \mathrm{PA} 1577$ is

370 classified as a Neanderthal.

371

372 4. Discussion

373 Increasing evidence from the morphological study of fossil hominins from China

374 suggests remarkable morphological variability toward the end of the Middle

375 Pleistocene (Bailey and Liu, 2010; Liu et al., 2013, 2017; Xing et al., 2014; Chang et

376 al., 2015; Martinón-Torres et al., 2018). Similarly, recent advances in the fields of

377 paleoproteomics and paleogenetics confirm the diversity of hominin groups that 
coexisted in this chronogeographic interval, including a sister group of Neanderthals: the Denisovans (Chen et al., 2019). However, taxonomic attributions of late Middle to early Late Pleistocene specimens and their interpretation in an evolutionary perspective

381 remain unclear (Bae, 2010; Liu et al., 2013; Kaifu, 2017). For the first time, through a novel geometric morphometric approach we analyzed the EDJ shape of a sample of hominin premolars from China spanning the Middle Pleistocene and compared this sample with other fossil and recent human groups.

At a large scale, our study reported at least two morphotypes in EDJ shape expressed in this time period: one displaying a $H$. erectus-like condition and the other showing a morphology that is closer to Late Pleistocene humans, sharing traits with both Neanderthals and modern humans. Irrespective of the taxon, in this timeframe, we also document a general trend towards a reduction of the crown base in relation to the occlusal basin, narrowing of the lingual aspect, and increasing of EDJ relief.

From the late Early to mid-Middle Pleistocene, we found a proportionally

392 broadened crown base associated with a smaller occlusal basin and low EDJ relief in

393 hominin premolars from Indonesia (Sangiran), Algeria (Tighenif) and China

394 (Zhoukoudian, Hexian, Xichuan and Yiyuan). This is also compatible with previous 395 studies suggesting a possible retention of Early Pleistocene hominin features (as seen 396 in Sangiran 4 for example) in Chinese Middle Pleistocene H. erectus (Xing et al., 2014, 397 2016; Liu et al., 2017; Zanolli et al., 2018). Thus, until the mid-Middle Pleistocene, 398 only one human group, likely related to H. erectus can be identified in China from the 

least two morphotypes. The first one is characterized by large crown base, centrally-

401 positioned dentine horn tips and low EDJ topography, together with a set of crowncomplexifying non-metric traits as seen in the specimens from Changyang (PA76 and

403 81) and Chaoxian. It is noteworthy that the Chaoxian $\mathrm{P}^{4}$ expresses H. erectus-like

404 features at the EDJ level that are in agreement with precious observations made on the outer crown morphology (Bailey and Liu, 2010). In light of these results, together with the similarities in EDJ shape of these specimens with $H$. erectus (Figs. 1 and 2), we interpret the Changyang and Chaoxian hominins as a late representative of an East Asian $H$. erectus lineage.

The second morphotype, represented by the fossils from Panxian Dadong and Tongzi, is characterized by a series of derived features generally found in Late

411 Pleistocene hominins, like Neanderthals and modern humans, as already suggested by 412 previous studies of the external tooth morphology (Liu et al., 2013; Pan et al., 2019;

413 Pan and Zanolli, 2019). The EDJ shape of PA873 and PA1578, even if intermediate

414 between the Neanderthal and modern human conditions, tends to show more affinities

415 with the Neanderthal general pattern. Even if there is no evidence for such an early 416 onset of dispersion into Asia, the recent finding from Misliya in Israel (Hershkovitz et 417 al., 2018) indicates that we cannot rule out the possibility that they may represent a 418 biogeographical variation of early modern humans in China. It is also possible that these 419 non-H. erectus Homo may sample a distinct lineage, possibly Denisovans. In fact, 
421 humans that lived from the Altai to East and South Asia (Meyer et al., 2012, 2016;

422 Jacobs et al., 2019; Mondal et al., 2019), were recently reaffirmed by the combined 423 morphological and molecular analyses of a mandible fragment from Xiahe, on the

424 Tibetan Plateau (Chen et al., 2019). As archaic Denisovans probably occupied a broad 425 geographical range, admixture between Denisovans and early modern humans probably 426 occurred not only in Siberia and Southeast Asia but also in Southern China (Reich et 427 al., 2011; Cooper and Stringer, 2013). Even if no Denisovan premolar is known yet, 428 given the current evidence, it is possible that the Panxian Dadong and Tongzi hominins 429 could belong to this taxon, as it was also proposed for other late Middle Pleistocene 430 specimens from Asia, like the human remains from Xujiayao (Xing et al., 2015, Chen 431 et al., 2019) and Penghu (Chang et al., 2015). Another possibility is that these 432 specimens sample representative from both Denisovans and Pleistocene modern 433 humans.

\section{Conclusions}

The present study suggests the existence of time-related evolutionary changes in

437 the premolar EDJ morphology in a number of Early and Middle Pleistocene hominin 438 groups, with special reference to mid- and late Middle Pleistocene populations in China.

439 A general trend towards a reduction of crown base in relation to occlusal aspects, 440 narrowed lingual aspects, heightened EDJ relief and a surface simplification is found 
441 through time. The current analysis expands our knowledge on the dental inner

442 morphology of Middle Pleistocene hominins, supports the coexistence of archaic

443 ('Homo erectus-like') and derived ('Late Pleistocene Homo-like') dental

444 morphological patterns and, through a dental perspective, suggest the preservation of

445 plesiomorphic, $H$. erectus-like morphology during the Middle Pleistocene. New fossil

446 discoveries and/or molecular analyses will be critical to explore further the past

447 diversity and to shed light on the dispersal and interaction of hominin populations in

448 East Asia.

\section{Acknowledgements}

This study is dedicated to the memory of our dear friend and coworker Pan Lei, who passed away

while this paper was being peer-reviewed. For access to specimens, we sincerely thank C. Argot, O.

454 Kullmer, E.N. L'Abbé, H. Lelièvre, W. Liu, A. Oettlé, F. Schrenk, C. Thèves, J.F. Tournepiche, S. Xing,

455 and C.K. Sun. The Musée of Angoulême kindly granted access for study and scanning to the specimens

456 from La Chaise Abri Bourgeois-Delaunay; for this, we are indebted to J.F. Tournepiche. These

457 specimens were scanned by A. Mazurier and R Macchiarelli at the ESRF beamline ID 17 (Grenoble) in

458 collaboration with A. Bravin, C. Nemoz and P. Tafforeau, and we thank them for sharing the

459 microtomographic records. For technical assistance, we are indebted to F. Bernardini, F. de Beer, B.

460 Duployer, J.W. Hoffman, and C. Tuniz. For scientific collaboration and discussion, we sincerely thank

461 Y.M. Hou, M. Kundrát, R. Macchiarelli, and S. Xing. We thank Y.X. Hao for his insightful comments 
Geology and Palaeontology, CAS; grant number 173119) and The French Centre National de la

\section{$474 \quad$ References}

475 Bae, C.J., 2010. The late Middle Pleistocene hominin fossil record of eastern Asia: synthesis and review. American Journal of Physical Anthropology 143(S51), 75-93.

477 Bailey, S.E., Liu, W., 2010. A comparative dental metrical and morphological analysis of a Middle Pleistocene hominin maxilla from Chaoxian (Chaohu), China.

480 Beaudet, A., Dumoncel, J., Thackeray, F., Bruxelles, L., Duployer, B., Tenailleau, C., 481 Bam, L., Hoffman, J., de Beer, F., Braga, J., 2016a. Upper third molar internal structural organization and semicircular canal morphology in Plio-Pleistocene South 
484 Beaudet, A., Dumoncel, J., De Beer, F., Duployer, B., Durrleman, S., Gilissen, E., 485 Hoffman, J., Tenailleau, C., Thackeray, J.F., Braga, J., 2016b. Morphoarchitectural 486 variation in South African fossil cercopithecoid endocasts. Journal of Human $487 \quad$ Evolution 101, 65-78.

488 Beaudet, A., Dumoncel, J., Beer, F., Durrleman, S., Gilissen, E., Oettlé, A., Subsol, G., 489 Thackeray, J.F., Braga, J., 2018. The endocranial shape of Australopithecus 490 africanus: surface analysis of the endocasts of Sts 5 and Sts 60. Journal of Anatomy 232, 296-303.

492

Bermúdez de Castro, J.M., Martinón-Torres, M., 2013. A new model for the evolution 493 of the human Pleistocene populations of Europe. Quaternary International 295, $102-$ 112.

Black, D., de Chardin, P.T., Young, C.C., Pei, W.C., Hao, W.W., 1933. Fossil Man in China. The Choukoutien cave deposits with a synopsis of our present knowledge of the late Cenozoic of China. The Geological Survey of China Series A 11, 1-158.

Bookstein, F., 1991. Morphometric Tools for Landmark Data: Geometry and Biology. Cambridge University Press, Cambridge.

500 Bookstein, F.L., 2019. Pathologies of between-groups principal components analysis in 501 geometric morphometrics. Evolutionary Biology 46, 271-302.

502 Braga, J., Thackeray, J.F., Subsol, G., Kahn, J.L., Maret, D., Treil, J., Beck, A., 2010. 503 The enamel-dentine junction in the postcanine dentition of Australopithecus 
504 africanus: intra-individual metameric and antimeric variation. Journal of Anatomy $505 \quad 216,62-79$.

506 Braga, J., Zimmer, V., Dumoncel, J., Samir, C., de Beer, F., Zanolli, C., Pinto, D., Rohlf, 507 F.J., Grine, F.E., 2019. Efficacy of diffeomorphic surface matching and 3D 508 geometric morphometrics for taxonomic discrimination of Early Pleistocene 509 hominin mandibular molars. Journal of Human Evolution 130, 21-35.

510 Cardini, A., O’Higgins, P., Rohlf, F.J., 2019. Seeing distinct groups where there are 511 none: spurious patterns from between-group PCA. Evolutionary Biology 46, 303512316

513 Cardini, A., Polly, P.D., 2020. Cross-validated between group PCA scatterplots: A 514 solution to spurious group separation? Evolutionary Biology 47, 85-95.

515 Chang, C.-H., Kaifu, Y., Takai, M., Kono, R.T., Grün, R., Matsu'ura, S., Kinsley, L., 516 Lin, L.-K., 2015. The first archaic Homo from Taiwan. Nature Communications 6, $517 \quad 6037$.

518 Chen, F., Welker, F., Shen, C.-C., Bailey, S.E., Bergmann, I., Davis, S., Xia, H., Wang, 519 H., Fischer, R., Freidline, S.E., 2019. A late Middle Pleistocene Denisovan mandible 520 from the Tibetan Plateau. Nature 569, 409-412.

521 Chen, T., Yuan, S., Gao, S., Hu, Y., 1987. Uranium series dating of fossil bones from 522 Hexian and Chaoxian fossil human sites. Acta Anthropologica Sinica 6, 249-254. 523 (In Chinese with English abstract)

524 Chia, L., 1957. Notes on the human and some other mammalian remains from 
525 Changyang, Hupei. Vertabrata PalAsiatica 1, 179-190.

526 Coleman, M.N., Colbert, M.W., 2007. CT thresholding protocols for taking 527 measurements on three-dimensional models. American Journal of Physical $528 \quad$ Anthropology 133, 723-725.

529 Cooper, A., Stringer, C., 2013. Did the Denisovans cross Wallace's line? Science 342, $530 \quad 321-323$.

531 Corruccini, R., 1987. The dentinoenamel junction in primates. International Journal of $532 \quad$ Primatology 8, 99-114.

533 Durrleman, S., Pennec, X., Trouvé, A., Ayache, N., Braga, J., 2012a. Comparison of 534 the endocranial ontogenies between chimpanzees and bonobos via temporal 535 regression and spatiotemporal registration. Journal of Human Evolution 62, 74-88.

536 Durrleman, S., Prastawa, M., Korenberg, J.R., Joshi, S., Trouvé, A., Gerig, G., 2012b.

537 Topology preserving atlas construction from shape data without correspondence 538 using sparse parameters. In: Ayache, N., Delingette, H., Golland, P., Mori, K. (Eds.), 539 Proceedings of Medical image Computing and Computer Assisted Intervention. $540 \quad$ Nice, France, pp. 223-230

541 Durrleman, S., Prastawa, M., Charon, N., Korenberg, J.R., Joshi, S., Gerig, G., Trouvé, 542 A., 2014. Morphometry of anatomical shape complexes with dense deformations 543 and sparse parameters. NeuroImage 101, 35-49.

544 Fajardo, R.J., Ryan, T., Kappelman, J., 2002. Assessing the accuracy of high-resolution 545 X-ray computed tomography of primate trabecular bone by comparisons with 
547 Glaunes, J.A., Joshi, S., 2006. Template estimation form unlabeled point set data and

548 surfaces for computational anatomy. In: Pennec, X., Joshi, S. (Eds.), 1st MICCAI

549 Workshop on Mathematical Foundations of Computational Anatomy: Geometrical,

550 Statistical and Registration Methods for Modeling Biological Shape Variability.

551 Copenhagen, pp. 29-39

552 Grine, F., 1994. Fossil hominid teeth from the Sangiran Dome (Java, Indonesia).

553 Courier Forschungsinstitut Senckenberg 171, 75-103.

554 Grün, R., Huang, P.-H., Wu, X., Stringer, C.B., Thorne, A.G., McCulloch, M., 1997.

555 ESR analysis of teeth from the palaeoanthropological site of Zhoukoudian, China.

$556 \quad$ Journal of Human Evolution 32, 83-91.

557 Grün, R., Huang, P.-H., Huang, W., McDermott, F., Thorne, A., Stringer, C.B., Yan, G., 558 1998. ESR and U-series analyses of teeth from the palaeoanthropological site of 559 Hexian, Anhui Province, China. Journal of Human Evolution 34, 555-564.

560 Han, F., Sun, C., Bahain, J.-J., Zhao, J., Lin, M., Xing, S., Yin, G., 2016. Coupled ESR 561 and U-series dating of fossil teeth from Yiyuan hominin site, northern China. 562 Quaternary International 400, 195-201.

563 Hershkovitz, I., Weber, G.W., Quam, R., Duval, M., Grün, R., Kinsley, L., Ayalon, A., 564 Bar-Matthews, M., Valladas, H., Mercier, N., 2018. The earliest modern humans $565 \quad$ outside Africa. Science 359, 456-459.

566 Jacobs, Z., Li, B., Shunkov, M.V., Kozlikin, M.B., Bolikhovskaya, N.S., Agadjanian, 
568 of archaic hominin occupation of Denisova Cave in southern Siberia. Nature 565, $569 \quad 594-599$.

570 Huang, P.-H., Jin, S.-Z., Peng, Z.-C., Liang, R.-Y., Lu, Z.-J., Wang, Z.-R., Chen, J.-B., 571 Yuan, Z.-X., 1993. ESR dating of tooth enamel: comparison with U-Series, FT and 572 TL dating at the Peking Man Site. Applied Radiation and Isotopes 44, 239-242.

573 Huffman, O.F., 2001. Geologic context and age of the Perning/Mojokerto Homo erectus, 574 East Java. Journal of Human Evolution 40, 353-362.

575 Kaifu, Y., Baba, H., Aziz, F., Indriati, E., Schrenk, F., Jacob, T., 2005. Taxonomic 576 affinities and evolutionary history of the Early Pleistocene hominids of Java: 577 Dentognathic evidence. American Journal of Physical Anthropology 128, 709-726.

578 Kaifu, Y., 2017. Archaic hominin populations in Asia before the arrival of modern 579 humans: their phylogeny and implications for the "Southern Denisovans". Current $580 \quad$ Anthropology 58, S418-S433.

581 Karkanas, P., Schepartz, L.A., Miller-Antonio, S., Wang, W., Huang, W., 2008. Late 582 Middle Pleistocene climate in southwestern China: inferences from the stratigraphic 583 record of Panxian Dadong Cave, Guizhou. Quaternary Science Reviews 27, 1555$584 \quad 1570$.

585 Liu, W., Schepartz, L.A., Xing, S., Miller-Antonio, S., Wu, X., Trinkaus, E., Martinón586 Torres, M., 2013. Late Middle Pleistocene hominin teeth from Panxian Dadong, 587 South China. Journal of Human Evolution 64, 337-355. 
589 Wu, X.-h., Edwards, R.L., Cheng, H., 2015. The earliest unequivocally modern 590 humans in southern China. Nature 526, 696-670.

591 Liu, W., Martinón-Torres, M., Kaifu, Y., Wu, X., Kono, R., Chang, C.-H., Wei, P., Xing, 592 S., Huang, W., Bermúdez de Castro, J.M., 2017. A mandible from the Middle 593 Pleistocene Hexian site and its significance in relation to the variability of Asian $594 \quad$ Homo erectus. American Journal of Physical Anthropology 162, 715-731.

595 Macchiarelli, R., Bondioli, L., Debénath, A., Mazurier, A., Tournepiche, J.-F., Birch, 596 W., Dean, C., 2006. How Neanderthal molar teeth grew. Nature 444, 748-751.

597 Macchiarelli, R., Bayle, P., Bondioli, L., Mazurier, A., Zanolli, C., 2013. From outer to 598 inner structural morphology in dental anthropology: integration of the third 599 dimension in the visualization and quantitative analysis of fossil remains, In: Scott, 600 G.R., Irish, J. (Eds.), Anthropological Perspectives on Tooth Morphology: Genetics, 601 Evolution, Variation. Cambridge University Press, Cambridge, pp. 250-277.

602 Martinón-Torres, M., Bermúdez de Castro, J.M., Gómez-Robles, A., Arsuaga, J.L., 603 Carbonell, E., Lordkipanidze, D., Manzi, G., Margvelashvili, A., 2007. Dental 604 evidence on the hominin dispersals during the Pleistocene. Proceedings of the $605 \quad$ National Academy of Sciences USA 104, 13279-13282.

606 Martinón-Torres, M., Bermúdez de Castro, J.M., Gómez-Robles, A., Margvelashvili, 607 A., Prado, L., Lordkipanidze, D., Vekua, A., 2008. Dental remains from Dmanisi 608 (Republic of Georgia): morphological analysis and comparative study. Journal of 
610 Martinón-Torres, M., Xing, S., Liu, W., Bermúdez de Castro, J.M., 2018. A “source and 611 sink" model for East Asia? Preliminary approach through the dental evidence. 612 Comptes Rendus Palevol 17, 33-43.

613 Matsu'ura, S., Kondo, M., Danhara, T., Sakata, S., Iwano, H., Hirata, T., Kurniawan, I., 614 Setiyabudi, E., Takeshita, Y., Hyodo, M., 2020. Age control of the first appearance 615 datum for Javanese Homo erectus in the Sangiran area. Science 367, 210-214.

616 Meyer, M., Kircher, M., Gansauge, M.-T., Li, H., Racimo, F., Mallick, S., Schraiber, 617 J.G., Jay, F., Prüfer, K., De Filippo, C., 2012. A high-coverage genome sequence 618 from an archaic Denisovan individual. Science 338, 222-226.

619 Meyer, M., Arsuaga, J.-L., de Filippo, C., Nagel, S., Aximu-Petri, A., Nickel, B., 620 Martínez, I., Gracia, A., Bermúdez de Castro, J.M., Carbonell, E., 2016. Nuclear 621 DNA sequences from the Middle Pleistocene Sima de los Huesos hominins. Nature $622531,504$.

623 Mondal, M., Bertranpetit, J., Lao, O., 2019. Approximate Bayesian computation with 624 deep learning supports a third archaic introgression in Asia and Oceania. Nature 625 Communications 10, 246.

626 NESPOS database, 2020, NEanderthal Studies Professional Online Service. 627 https://www.nespos.org.

628 Pan, L., Dumoncel, J., de Beer, F., Hoffman, J., Thackeray, J.F., Duployer, B., 629 Tenailleau, C., Braga, J., 2016. Further morphological evidence on South African 
630 earliest Homo lower postcanine dentition: enamel thickness and enamel dentine 631 junction. Journal of Human Evolution 96, 82-96.

632 Pan, L., Thackeray, J.F., Dumoncel, J., Zanolli, C., Oettlé, A., De Beer, F., Hoffman, J., 633 Duployer, B., Tenailleau, C., Braga, J., 2017. Intra-individual metameric variation 634 expressed at the enamel-dentine junction of lower post-canine dentition of South 635 African fossil hominins and modern humans. American Journal of Physical 636 Anthropology 163, 806-815.

637 Pan, L., Zanolli, C., 2019. Comparative observations on the premolar root and pulp 638 canal configurations of Middle Pleistocene Homo in China. American Journal of 639 Physical Anthropology 168, 637-646.

640 Pan, L., Dumoncel, J., Mazurierd, A., Zanolli, C., 2019. Structural analysis of premolar 641 roots in Middle Pleistocene hominins from China. Journal of Human Evolution 136, 642102669.

643 R Development Core Team, 2012. R: A language and environment for statistical 644 computing. R Foundation for Statistical Computing, Vienna.

645 Radovčić, J., Smith, F.H., Trinkaus, E., Wolpoff, M.H., 1988. The Krapina Hominids: 646 An Illustrated Catalog of Skeletal Collection. Mladost and the Croatian Natural 647 History Museum, Zagreb.

648 Reich, D., Patterson, N., Kircher, M., Delfin, F., Nandineni, M.R., Pugach, I., Ko, A.M.649 S., Ko, Y.-C., Jinam, T.A., Phipps, M.E., 2011. Denisova admixture and the first 650 modern human dispersals into Southeast Asia and Oceania. The American Journal 
Rink, W.J., Schwarcz, H.P., Smith, F.H., Radovčić, J., 1995. ESR dates for Krapina 653 hominids. Nature 378, 24.

654 Sahnouni, M., Van der Made, J., 2009. The Oldowan in North Africa within a 655 biochronological framework. In: Schick, K., Toth, N. (Eds.), The Cutting Edge: New 656 Approaches to the Archaeology of Human Origins. Stone Age Institute Press, 657 Bloomington, pp. 179-210.

658 Schlager, S., Profico, A., Di Vincenzo, F., Manzi, G., 2018. Retrodeformation of fossil 659 specimens based on 3D bilateral semi-landmarks: Implementation in the R package 660 “Morpho”. PLoS One 13, e0194073.

661 Scott, G.R., Turner, C.G., 1997. The Anthropology of Modern Human Teeth: Dental 662 Morphology and its Variation in Recent Human Populations. Cambridge University 663 Press, Cambridge.

664 Shen, G., Jin, L., 1991. U-series age of Yanhui Cave, the site of Tongzi Man. Acta 665 Anthropologica Sinica 10, 65-72.

666 Shen, G., Fang, Y., Bischoff, J.L., Feng, Y.-x., Zhao, J.-x., 2010. Mass spectrometric U667 series dating of the Chaoxian hominin site at Yinshan, eastern China. Quaternary $668 \quad$ International 211, 24-28.

669 Skinner, M.M., Wood, B.A., Boesch, C., Olejniczak, A.J., Rosas, A., Smith, T.M., 670 Hublin, J.-J., 2008a. Dental trait expression at the enamel-dentine junction of lower 671 molars in extant and fossil hominoids. Journal of Human Evolution 54, 173-186. 
672 Skinner, M.M., Gunz, P., Wood, B.A., Hublin, J.-J., 2008b. Enamel-dentine junction 673 (EDJ) morphology distinguishes the lower molars of Australopithecus africanus and $674 \quad$ Paranthropus robustus. Journal of Human Evolution 55, 979-988.

675 Skinner, M.M., 2008. Enamel-dentine junction morphology of extant hominoid and 676 fossil hominin lower molars. Ph.D. Dissertation, George Washington University.

677 Smith, B.H., 1984. Patterns of molar wear in hunter-gatherers and agriculturalists. 678 American Journal of Physical Anthropology 63, 39-56.

679 Turner, C.G., Nichol, C.R., Scott, G.R., 1991. Scoring procedures for key 680 morphological traits of the permanent dentition: the Arizona State University dental 681 anthropology system, In: Kelley, M.A., Larsen, C.S. (Eds.), Advances in Dental 682 Anthropology. Wiley-Liss, New York, pp. 31-31.

683 Urciuoli, A., Zanolli, C., Beaudet, A., Dumoncel, J., Santos, F., Moyà-Solà, S., Alba, 684 D.M., 2020. The evolution of the vestibular apparatus in apes and humans. eLife 9, 685 e51261.

686 Weber, W.G., 2001. Virtual anthropology (VA): A call for Glasnost in 687 paleoanthropology. The Anatomical Record 265, 193-201.

688 Weber, G.W., 2015. Virtual anthropology. American Journal of Physical Anthropology $689 \quad 156,22-42$.

690 Weidenreich, F., 1937. The dentition of Sinanthropus pekinensis: a comparative 691 odontography of the hominids. Palaeontologia Sinica D 1, 1-180.

692 Wu, M.-L., 1984. New discoveries of human fossil in Tongzi, Guizhou. Acta 
694 Wu, X., Wu, R., 1982. Human fossil teeth from Xichuan, Henan. Vertabrata PalAsiatica 695 20, 1-10. (In Chinese with English abstract)

696 Wu, X., Poirier, F.E., 1995. Human evolution in China: a metric description of the 697 fossils and a review of the sites. Oxford University Press, New York.

698 Xing, S., 2012. Morphological variation of Zhoukoudian H. erectus teeth. Ph.D. 699 Dissertation, Graduate University of Chinese Academy of Sciences.

700 Xing, S., Martinón-Torres, M., Bermúdez de Castro, J.M., Zhang, Y., Fan, X., Zheng, 701 L., Huang, W., Liu, W., 2014. Middle Pleistocene hominin teeth from Longtan Cave, $702 \quad$ Hexian, China. PLoS One 9, e114265.

703 Xing, S., Martinón-Torres, M., Bermúdez de Castro, J.M., Wu, X., Liu, W., 2015. 704 Hominin teeth from the early Late Pleistocene site of Xujiayao, Northern China. 705 American Journal of Physical Anthropology 156, 224-240.

706 Xing, S., Sun, C., Martinón-Torres, M., Bermúdez de Castro, J.M., Han, F., Zhang, Y., 707 Liu, W., 2016. Hominin teeth from the Middle Pleistocene site of Yiyuan, Eastern 708 China. Journal of Human Evolution 95, 33-54.

709 Xing, S., Martinón-Torres, M., Bermúdez de Castro, J.M., 2018. The fossil teeth of the $710 \quad$ Peking Man. Scientific Reports 8, 2066.

711 Xing, S., Martinón-Torres, M., Bermúdez de Castro, J.M., 2019. Late Middle 712 Pleistocene hominin teeth from Tongzi, southern China. Journal of Human 713 Evolution 130, 96-108. 
714 Yuan, S., Chen, T., Gao, S., 1986. Uranium series chronological sequence of some 715 palaeolithic sites in South China. Acta Anthropologica Sinica 2, 179-190. (In $716 \quad$ Chinese with English abstract)

717 Zanolli, C., Bondioli, L., Mancini, L., Mazurier, A., Widianto, H., Macchiarelli, R., 718 2012. Brief communication: Two human fossil deciduous molars from the Sangiran 719 Dome (Java, Indonesia): Outer and inner morphology. American Journal of Physical $720 \quad$ Anthropology 147, 472-481.

721 Zanolli, C., Mazurier, A., 2013. Endostructural characterization of the $H$. 722 heidelbergensis dental remains from the early Middle Pleistocene site of Tighenif, 723 Algeria. Comptes Rendus Palevol 12, 293-304.

724 Zanolli, C., 2013. Additional evidence for morpho-dimensional tooth crown variation 725 in a New Indonesian $H$. erectus sample from the Sangiran Dome (Central Java). $726 \quad$ PLoS One 8, e67233.

727 Zanolli, C., Pan, L., Dumoncel, J., Kullmer, O., Kundrát, M., Liu, W., Macchiarelli, R., 728 Mancini, L., Schrenk, F., Tuniz, C., 2018. Inner tooth morphology of Homo erectus 729 from Zhoukoudian. New evidence from an old collection housed at Uppsala 730 University, Sweden. Journal of Human Evolution 116, 1-13.

731 Zanolli, C., Kullmer, O., Kelley, J., Bacon, A.-M., Demeter, F., Dumoncel, J., Fiorenza, 732 L., Grine, F.E., Hublin, J.-J., Tuan, N., Nguyen Thi, M.H., Pan, L., Schillinger, B., 733 Schrenk, F., Skinner, M.M., Xueping, J., Macchiarelli, R., 2019. Evidence for 734 increased hominid diversity in the Early-Middle Pleistocene of Java, Indonesia. 
735 Nature Ecology and Evolution 3, 755-764. 


\section{Table 1}

Composition of the study specimens from China and of the comparative samples.

\begin{tabular}{|c|c|c|c|c|c|c|c|}
\hline Chinese Pleistocene specimens & $\mathrm{P}^{3}$ & $\mathrm{P}^{4}$ & $\mathrm{P}_{3}$ & $\mathrm{P}_{4}$ & Provenance & Chronological range $^{\text {a }}$ & Citations $^{\mathrm{b}}$ \\
\hline \multicolumn{8}{|c|}{ Middle Pleistocene Homo erectus from China (HEC) } \\
\hline PA67 & 1 & & & & Zhoukoudian Loc. 1 (Layer 11) & $800-770$ (A) & $1-3$ \\
\hline PA68 & & 1 & & & Zhoukoudian Loc. 1 (Layer 11) & $800-770$ (A) & $1-3$ \\
\hline PMU M3549 & & & 1 & & Zhoukoudian Loc. 1 (Layer 5) & $550-500 \mathrm{Ka}(\mathrm{B})$ & 2,4 \\
\hline PMU M3887 & & & & 1 & Zhoukoudian Loc. 1 (Layer 5) & $550-500 \mathrm{Ka}(\mathrm{B})$ & 2,4 \\
\hline PA1 $10^{c}$ & & & 1 & & Zhoukoudian Loc. 1 (Layer 3) & $320-282 \mathrm{ka}(\mathrm{C}, \mathrm{D}) ; 500 \mathrm{ka}(\mathrm{E})$ & $1-3$ \\
\hline $\mathrm{PA} 832^{\mathrm{c}}$ & 1 & & & & Hexian & 437-387 ka (B) & 5,6 \\
\hline Shy071 ${ }^{\mathrm{c}}$ & & 1 & & & Yiyuan & $420-320 \mathrm{ka}(\mathrm{F})$ & $7-9$ \\
\hline PA524 ${ }^{\mathrm{c}}$ & 1 & & & & Xichuan & Unknown & 10 \\
\hline PA525 ${ }^{\mathrm{c}}$ & & & & 1 & Xichuan & Unknown & 10 \\
\hline PA526 ${ }^{\mathrm{c}}$ & & & 1 & & Xichuan & Unknown & 10 \\
\hline PA527 ${ }^{c}$ & & & 1 & & Xichuan & Unknown & 10 \\
\hline PA528 & & & & 1 & Xichuan & Unknown & 10 \\
\hline
\end{tabular}


Late Middle Pleistocene Homo sp. from China (HSPC)

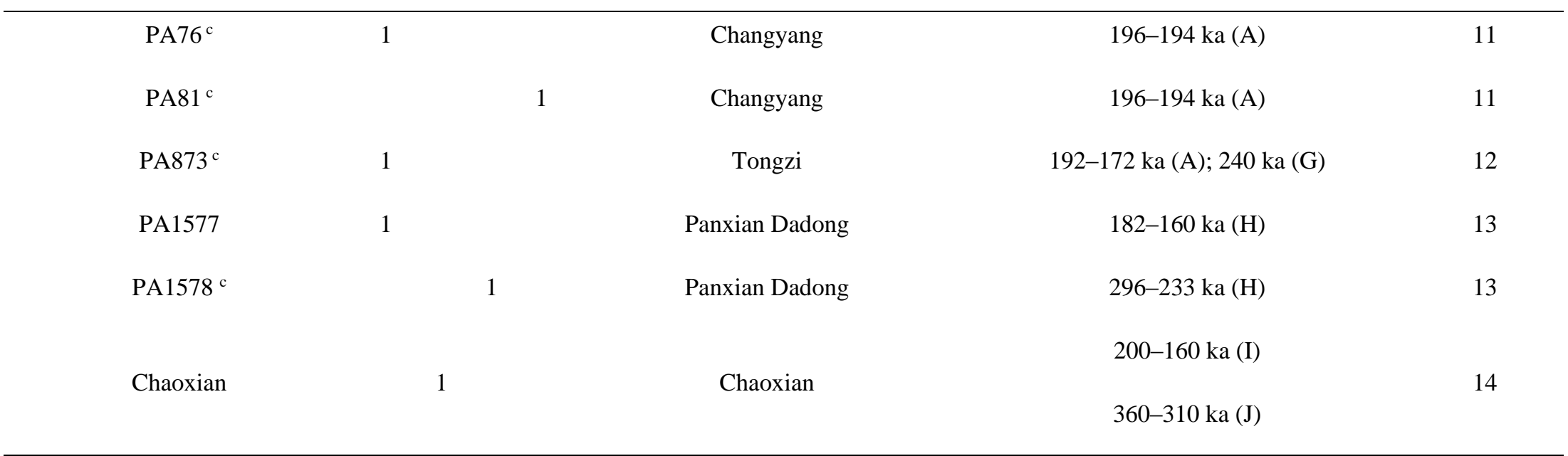

Comparative samples

Early Pleistocene H. erectus

from Java (HEJ)

\section{Sangiran 4}

Sangiran 7-3a

North Africa (HNA)

Tighenif 2

Neanderthals (NEA)
22

1
Sangiran (Pucangan Fm).

Sangiran (Pucangan Fm).
$1.8-1.6 \mathrm{Ma}(\mathrm{K})$

$\sim 1.3 \mathrm{Ma}(\mathrm{L})$

15

$\sim 1.0 \mathrm{Ma}(\mathrm{M})$

$140-120 \mathrm{ka}(\mathrm{N})$
16

17,18 


\begin{tabular}{ccccccccc} 
& & 1 & 2 & 1 & $\begin{array}{c}\text { La Chaise-de-Vouthon (Abri } \\
\text { Bourgeois-Delaunay) }\end{array}$ & $146-106 \mathrm{ka}(\mathrm{O})$ & 18,19 \\
Recent modern humans (RMH) & 10 & 6 & 11 & 8 & Asia/ Europe/South Africa & 20 \\
\hline
\end{tabular}

a Age references: A = Yuan et al. (1986); B = Grün et al. (1998); C = Grün et al. (1997); D = Huang et al. (1993); E = Shen et al. (2001); F = Han et al. (2016); G = Shen and Jin (1991); H = Karkanas et al. (2008); I = Chen et al. (1987); J = Shen et al. (2010); K = Huffman (2001); L = Matsu'ura et al. (2020); M = Sahnouni and Van der Made (2009); N = Rink et al. (1995); O = Macchiarelli et al. (2006).

${ }^{\mathrm{b}}$ Citations reporting descriptions of the morphology of the specimens : 1 = Xing (2012); 2 = Xing et al. (2018); 3 = Black et al. (1933); $4=$ Zanolli et al. (2018a); $5=$ Xing et al. (2014); $6=$ Liu et al. (2017); $7=$ Chen et al. (1987); $8=\mathrm{Wu}$ and Wu (1982); $9=$ Xing et al. $(2016) ; 10=\mathrm{Wu}$ and Wu (1982); $11=\mathrm{Chia}(1957) ; 12=$ Xing et al. (2019); 13 =Liu et al. (2013); 14 = Bailey and Liu (2010); 15 = Grine (1994); 16 = Zanolli and Mazurier (2013); $17=$ Radovčić et al. (1988); 18 = NESPOS database (2020); 19 = Macchiarelli et al. (2006); 20 = Pan et al. (2017).

${ }^{\mathrm{c}}$ Worn crown, reconstructed dentine horn tips. For the reconstruction see SOM Figure S1. 


\section{Table 2}

2 Results of the cross-validation analyses performed on the between-group principal component scores.

3 The posterior probabilities that the Chinese specimens are closer to any group were then calculated. The

4 highest probabilities are indicated in bold (the greater the number, the higher the probability).

5

\begin{tabular}{cccc}
\hline Dental position & Specimen & Predictive accuracy of comparative specimens & Classification of the investigated Chinese fossils \\
\hline $\mathrm{P}^{3}$ & PA76 & HE: $100 \%$; NEA: $100 \%$, MHS: $100 \%$ & HE: 0.061; NEA: $<0.001$; MHS $<0.001$ \\
& PA873 & HE: $100 \%$; NEA: $100 \%$, MHS: $100 \%$ & HE: $<0.001$; NEA: 0.001;MHS: 0.002 \\
& PA1577 & HE: $100 \%$; NEA: $100 \%$, MHS: $100 \%$ & HE: $<0.01$; NEA: 0.104; MHS: $<0.001$ \\
\hline $\mathrm{P}^{4}$ & Chaoxian & HE: $100 \%$; NEA: $80 \%$, MHS: $80 \%$ & HE: 0.334; NEA: 0.001 ; MHS: $<0.001$ \\
$\mathrm{P}_{3}$ & PA1578 & HE: $100 \%$; NEA: $100 \%$, MHS: $91 \%$ & HE: $<0.001$; NEA: 0.004; MHS: 0.026 \\
\hline $\mathrm{P}_{4}$ & PA81 & HE: $100 \%$; NEA: $100 \%$, MHS: $88 \%$ & HE: $\mathbf{0 . 8 0 8}$;EA: $<0.001$ MHS: $<0.001$ \\
\hline
\end{tabular}

6

7

8

9

10

11

12

13

14 Abbreviations: $\mathrm{HE}=$ Homo erectus from Asia and late Early Pleistocene Homo from North Africa; NEA

$15=$ Neanderthals; MHS = modern Homo sapiens.

16 
19 Figure 1. Volume rendering of upper premolar EDJ of Homo erectus from China (HEC),

20 late Middle Pleistocene Homo sp. from China (HSPC), Javanese H. erectus (HEJ),

21 Neanderthals (NEA) and modern Homo sapiens (MHS). Occlusal view (right) and

22 mesial view (left), with dentine horn tips restored. The 3D models of left teeth (marked

23 by an asterisk) were mirrored to the right side for comparison. Abbreviations: $b=$

24 buccal; 1 = lingual; $\mathrm{m}=$ mesial.

25

26 Figure 2. Volume rendering of lower premolar EDJ of Homo erectus from China (HEC),

27 late Middle Pleistocene Homo sp. from China (HSPC), late Early Pleistocene Homo

28 from North Africa (HNA), Neanderthals (NEA) and modern Homo sapiens (MHS).

29 Occlusal view (right) and mesial view (left), with dentine horn tips restored. The 3D

30 models of left teeth (marked by an asterisk) were mirrored to the right side for

31 comparison. Abbreviations: $\mathrm{b}=$ buccal $; \mathrm{l}=$ lingual; $\mathrm{m}=$ mesial.

32

33 Figure 3. Principal component analysis (PCA) and between-group principal component

34 analysis (bgPCA) of the $\mathrm{P}^{3}(\mathrm{~A}, \mathrm{~B})$ and $\mathrm{P}^{4}(\mathrm{C}, \mathrm{D})$ enamel-dentine junction (EDJ)

35 morphology using diffeomorphism surface matching (DSM) approach. The extreme

36 shapes are illustrated in occlusal and mesial views at the end of each axis. Abbreviations:

37 HEC = Homo erectus from China; HEJ = Javanese H. erectus; NEA = Neanderthals; 

MHS = modern Homo sapiens .

40 Figure 4. Principal component analysis (PCA) and between-group principal component

41 analysis (bgPCA) of the $\mathrm{P}_{3}(\mathrm{~A}, \mathrm{~B})$ and $\mathrm{P}_{4}(\mathrm{C}, \mathrm{D})$ enamel-dentine junction (EDJ)

42 morphology using diffeomorphism surface matching (DSM) approach. The extreme

43 shapes are illustrated in occlusal and mesial views at the end of each axis. Abbreviations:

44 HEC = Homo erectus from China HNA = late Early Pleistocene Homo from North

45 Africa; $\mathrm{NEA}=$ Neanderthals , MHS = modern Homo sapiens. 


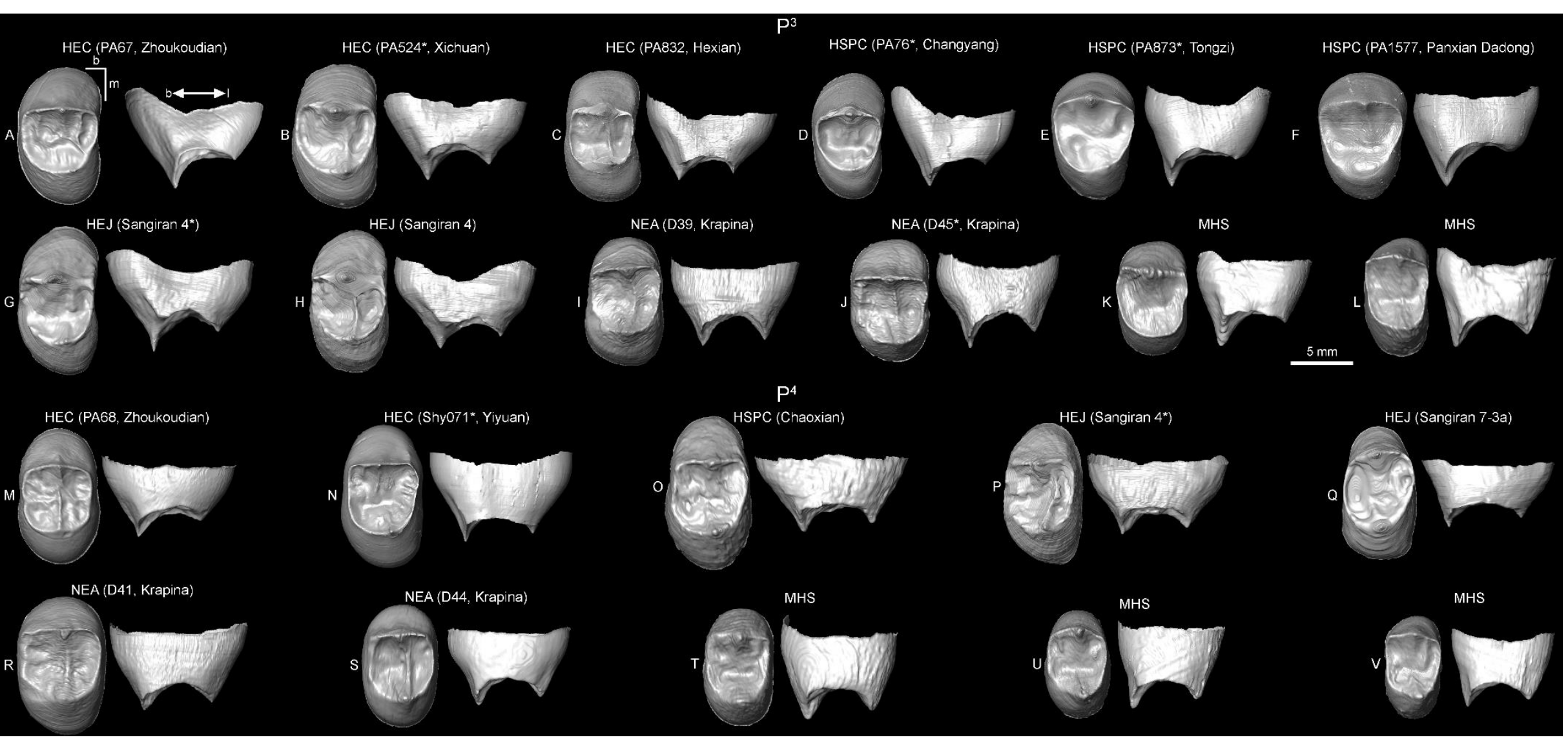



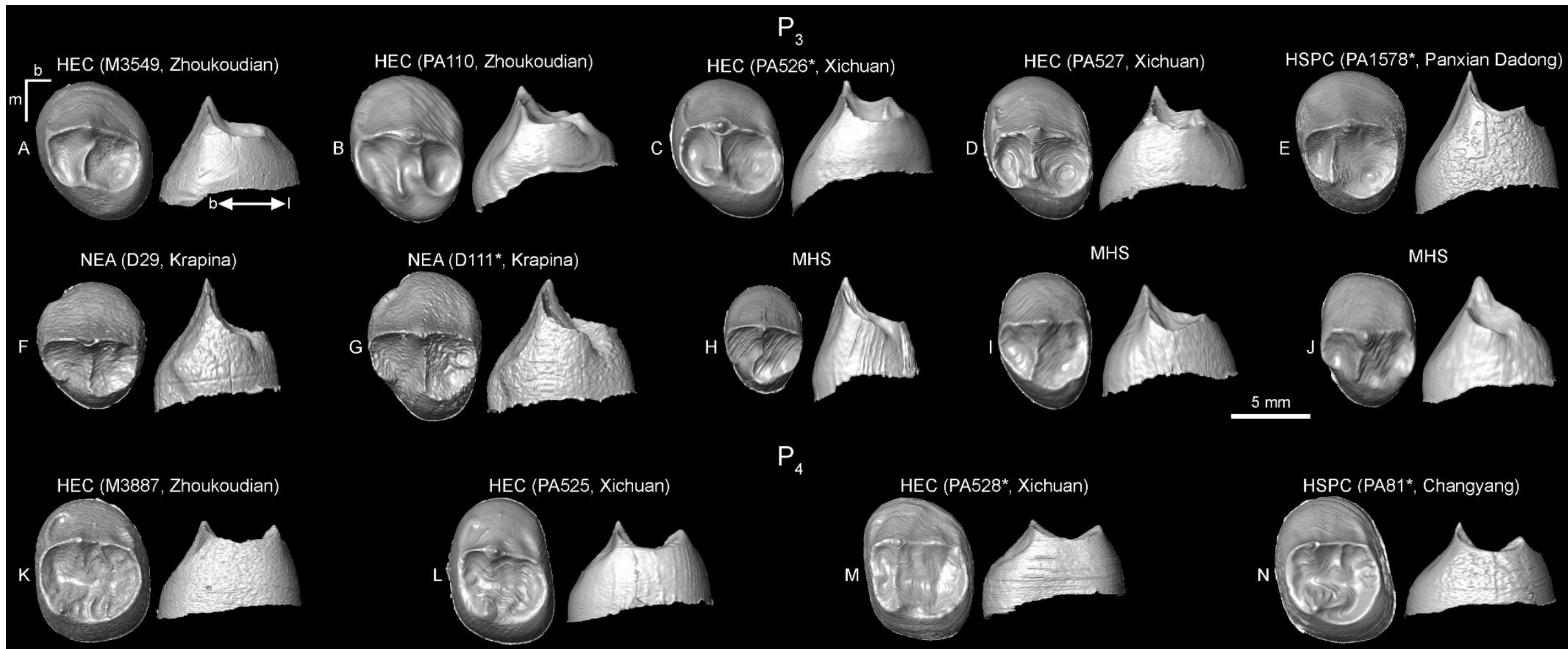

$\mathrm{P}_{4}$
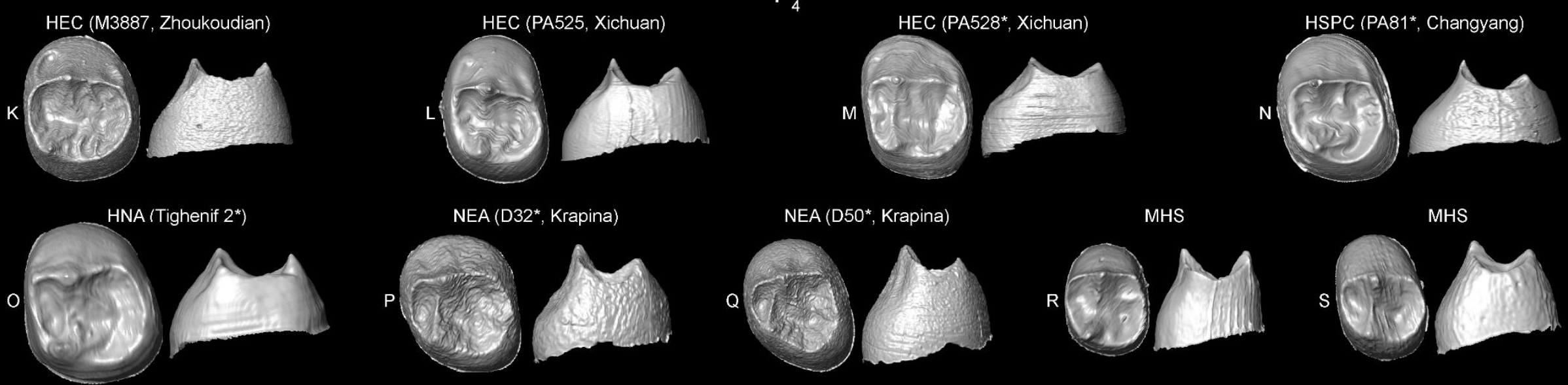

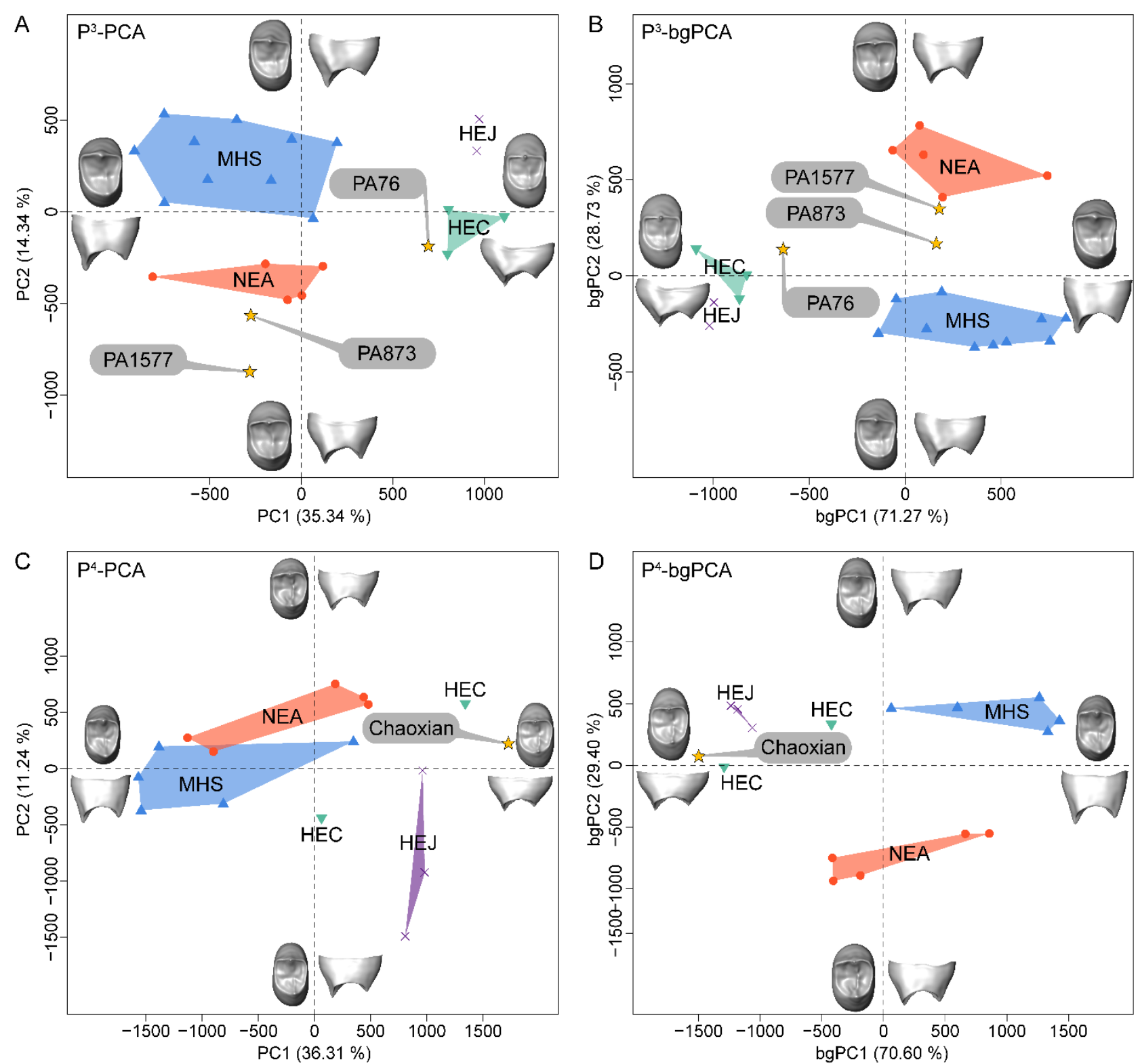

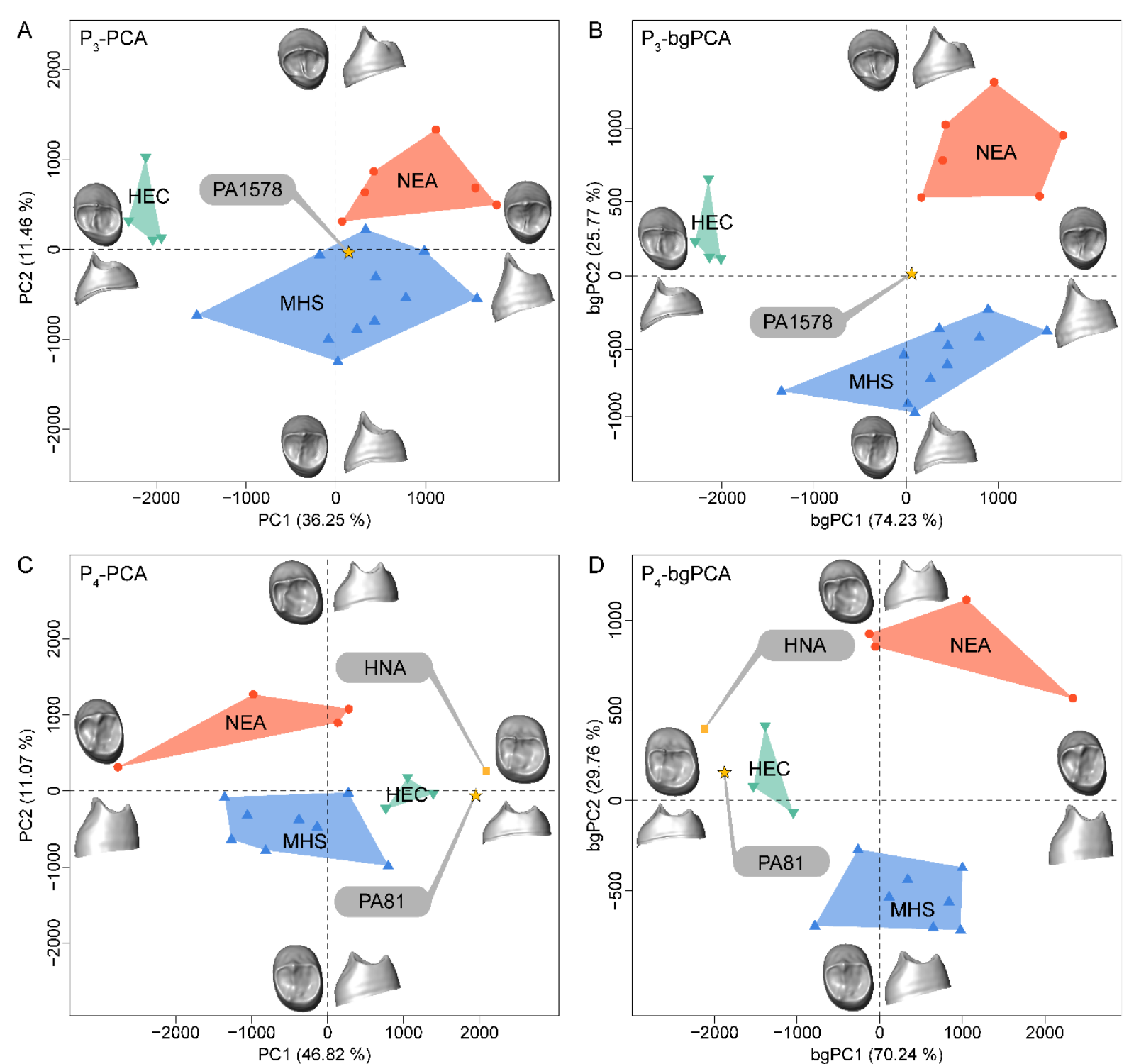